\title{
CENTRAIS DE NEGÓCIOS DE PEQUENAS EMPRESAS DO SETOR SUPERMERCADISTA: ENTRE A CONCORRÊNCIA E A COOPERAÇÃO
}

\author{
Natália Máximo e Melo*
}

Resumo: As mudanças nas formas de organização empresarial geram discussões não apenas com respeito às grandes empresas. Desde meados da década de 90 tem se difundido no Brasil o "associativismo" entre empresas de pequeno porte em vários setores de atividade, por exemplo, supermercados, farmácias, papelarias, etc. Conhecidas como "redes" $e$ denominadas mais precisamente por centrais de negócios, constituem-se em um conjunto de empresas que realizam compras em comum. O grande desafio das centrais de negócios é conciliar a concorrência e a cooperação e compreender esta relação é o objetivo da presente pesquisa. A pesquisa documental e empírica demonstra que a adesão ao associativismo em forma de central de negócios leva os empresários a terem contato com outras instituições sociais, acesso a novas informações, filiação à Associação de Supermercados dos estados e mudanças no padrão de negociação.

Palavras-chave: pequenas empresas, centrais de negócios, supermercados.

\begin{abstract}
The changes at the structures of business organizations generate debates not only about big companies. Since middle of 1990's, it has been widespread in Brazil networkings among small businesses in sector like supermarkets, pharmacies, libraries, etc. Known as "networks" and more specifically called business centers, they are groups of firms which make boughts in common. The great challenge for business centers is to combine competition and cooperation and to understand this relation is the goal of this research. Documental and empirical researches show that joining association in form of business centers takes owners at relations with other social institutions, access to new information, to Supermarkets Associations in several states and produces changes in the pattern of trading.
\end{abstract}

Keywords: small business, business centers, supermarkets

\section{Introdução}

Este artigo irá abordar a formação de uma central de negócios em São Carlos no setor de supermercados. É resultado de um estudo de caso que tem por intuito levantar questões

\footnotetext{
* Pesquisadora do Núcleo de Estudos de Sociologia Econômica e das Finanças da Universidade Federal de São Carlos - UFSCAR.
} 
sociológicas acerca do fenômeno das centrais de negócios e contribuir com discussões no âmbito da sociologia econômica.

Tomando como herança as análises dos estudos clássicos, a sociologia do mercado capitalista tem demonstrado que este não é uma construção abstrata e que não existem mercados perfeitos como algo natural e espontâneo, mas sim construções sociais que dependem das relações e instituições sociais locais.

Granovetter (2003) faz a crítica às análises subssocializadas dos mercados por levarem em conta apenas a ação individual e darem pouca importância ao contexto social das ações. Por outro lado, há análises sobressocializadas nas quais os constrangimentos sociais fazem com que a ação individual se dilua e desapareça. Diante dos limites de cada uma destas abordagens, Granovetter propõe que os fatos econômicos sejam entendidos enquanto redes de relações incrustadas nas demais relações sociais.

É desta forma que Granovetter consegue conciliar análises que levam em conta a ação individual sem desconsiderar o peso das estruturas sociais. É dentro delas e por meio delas que relações econômicas são possíveis. Ele analisa redes de relações, o que lhe permite superar as falhas de ambas as perspectivas teóricas. Pelas redes, os indivíduos se conectam à estrutura social. Analisar redes permite reconstituir os tipos e durações das relações sociais que indivíduos travam entre si e com grupos.

Granovetter (2003) distingue relações denominadas laços fortes de outras que são laços fracos. As primeiras constituem vínculos de coesão como, por exemplo, na família, na religião, amizades e tem caráter duradouro. Já os laços fracos se referem às relações indiretas que são estabelecidas por intermédio de outrem. Granovetter demonstrou, por exemplo, que os laços fracos têm papel muito importante para que indivíduos alcancem melhores postos de emprego.

O conceito de redes é de grande valia na análise dos mais variados fatos sociais em que está posta a ação de indivíduos em relação a outros. Mostra-se de importância em estudos de fatos econômicos do ponto de vista sociológico.

Estudos relativos à organização de pequenas empresas freqüentemente utilizam o conceito de rede como, por exemplo, na análise dos Distritos industriais e os Arranjos produtivos locais, muitas vezes ligados a processos de reestruturação produtiva das grandes empresas ou a estímulos governamentais de desenvolvimento local (ALBAGLI e MACIEL 2003; CASSIOLATO e LASTRES, 2003).

INTRATEXTOS, Rio de Janeiro. vol.2, nº 1, pp. 76 - 96, 2010. 
Apesar de serem identificadas como pequenas empresas, os supermercados que foram objeto do presente estudo não se confundem com os arranjos acima mencionados, pois são empresas comerciais e não industriais. Apesar de não estarem concentradas em uma localidade, também podem ser estudados a partir do conceito de rede. Assim, o presente estudo se baseia no conceito de rede de Granovetter a fim de compreender a formação das relações entre empresários de uma central de negócios do setor supermercadista ${ }^{1}$.

As redes, enquanto conjunto de interações entre atores sociais, não são estáticas nem fechadas. São construídas ao longo do tempo e são abertas à entrada ou saída dos seus membros. É segundo esta perspectiva que podemos entender a associação de supermercados aqui analisada.

A pesquisa foi desenvolvida principalmente a partir da coleta de documentos na Associação Brasileira de Supermercados (ABRAS), por exemplo, notícias de jornal e revistas, desde 2001, que havia no arquivo, também foram utilizados dados estatísticos produzidos pela ABRAS que avaliam as centrais de negócios do país. Além disso, conversei informalmente com o comprador da Central de negócios em São Carlos o qual me disponibilizou contatos dos supermercadistas associados. Por fim, entrevistei associados e não associados da central de negócios são-carlense.

Entende-se que o conceito de redes permite explicar as relações entre empresários de uma central de negócios. Além disso, um estudo comparativo permitirá compreender as percepções dos empresários quanto ao que consideram "cooperação" e competição que travam a partir dos laços sociais que constroem entre si e os outros.

\section{MPE e as Centrais de Negócios}

Os estudos existentes sobre MPEs se baseiam principalmente nos documentos da Relação Anual de Informações Sociais (RAIS), o qual permite quantificar o número de empresas existentes e os aspectos relativos à ocupação e remuneração da mão de obra formalizada. Também o SEBRAE divulga estudos sobre as MPEs. Os critérios para definir porte de empresas são bastante variáveis tanto por parte da legislação específica quanto por instituições financeiras e órgãos representativos do setor. Ora baseiam-se no valor do

\footnotetext{
${ }^{1}$ Vale a ressalva de que não se pode confundir o termo rede enquanto conceito sociológico e "Rede" enquanto concepção e nome pelo qual um conjunto de empresas é identificado. Esta concepção estará presente com frequiência na fala dos empresários como uma forma de auto-identificação.
} 
faturamento, ora no número de pessoas ocupadas e às vezes em ambos. Isso se deve ao fato de que a finalidade e os objetivos das instituições são distintos (regulamentação, crédito, estudos, etc).

Apesar disto, as estatísticas apontam para a importância crescente deste segmento de empresa nas atividades econômicas e de geração de empregos no Brasil. Tomando o período de 1996 a 2002, os dados do Boletim Estatístico do SEBRAE apontam que houve um crescimento de 55,8\% no total de número de microempresas e sua participação no total de empresas passou de 93,2\% em 96 para 93,6\% em 2002. E em 2006 apresenta a existência de 1,5 milhão de MPEs em São Paulo o que corresponde a 98\% do total de empresas no estado.

As centrais de negócios são encontradas principalmente entre pequenas empresas e se configuram como um novo formato de organização destas empresas. Pesquisa da ABRAS estima que $70 \%$ do volume de negócios das redes supermercadistas do país esteja concentrado na região Sudeste. A primeira rede de compras entre supermercados, no Brasil, surgiu há mais ou menos 27 anos em Vitória (ES). Em São Paulo, a primeira surgiu em 1994.

Segundo Flávia Ghisi, as primeiras redes de compras surgiram com objetivo apenas de conseguir melhores relações com seus fornecedores: "inicialmente, esse modelo sofreu severas críticas, pois muitos acreditavam que ele poderia destruir o relacionamento das empresas com seus distribuidores, na guerra por margens de lucro" (GHISI, 2005, p. 99).

Posteriormente, as redes de compras passaram a ser chamadas de centrais de negócios uma vez que suas atividades não se restringem mais unicamente a compras em conjunto, também podem fazer parte das atividades de uma central de negócios: serviço de marketing e promoções, padronização do mix de produtos, recrutamento e treinamento de empregados, padronização de lojas e uniformes, centro de distribuição de mercadorias aos associados, cartão de crédito conjunto e fabricação de produtos marca própria. Ainda segundo Ghisi (2005), estima-se que os descontos conseguidos pelas centrais girem em torno de 5 a $8 \%$, e que o aumento das vendas chegue até a $30 \%$.

Apesar de experiências como essa já existirem na Europa desde a década de 20, foi só nos anos 90 que se difundiu no mundo. No Brasil, se fundiu ao termo associativismo e tem sido difundido em vários ramos de atividade econômica como farmácia, supermercado, papelaria, construção, etc. Dados de 2003 mostram que de um total de cerca 260 centrais espalhadas pelo Brasil, há cerca de 150 centrais no setor de supermercados, 20 de farmácias, 60 de padarias, 20 de mini mercados, 15 de material de construção. 
A ABRAS produz uma pesquisa anual desde 2002 sobre as centrais de negócios de modo a avaliar o desempenho deste segmento do setor supermercadista brasileiro. As pesquisas apontam que o segmento das centrais e redes de supermercados tiveram nos últimos anos um crescimento (10,7\% real) maior do que a média do setor supermercadista como um todo $(0,9 \%$ real $)$ até 2007 . Há 10 anos a representatividade das redes no setor supermercadista no total faturado era de 3\%, em 2009 foi para 13,3\%. As empresas em redes apresentam índices próximos aos das 300 maiores empresas supermercadistas. Ainda segundo a ABRAS, $57 \%$ das centrais foram formadas entre os anos de 2000 e 2005, ou seja, é um fenômeno ainda recente. Em 2000, constavam 60 centrais de negócios no setor supermercadista no Brasil, em 2005 já eram 150 e em 2009 eram cerca de 130.

A seguir dados sobre a trajetória econômica das centrais de negócios a partir da pesquisa da ABRAS.

Dados Históricos 2000/2009

\begin{tabular}{|c|c|c|c|c|c|c|c|c|c|c|}
\hline & 2000 & 2001 & 2002 & 2003 & 2004 & 2005 & 2006 & 2007 & 2008 & 2009 \\
\hline $\begin{array}{l}\text { Faturamento } \\
\text { Bruto } \\
(\mathbf{R} \$ \mathbf{b i})^{*}\end{array}$ & $2 \mathrm{bi}$ & $3 \mathrm{bi}$ & 8,2 & 10,15 & 12,02 & 14,2 & 15,9 & 17,65 & 19,84 & 21,09 \\
\hline $\begin{array}{l}\text { Número de } \\
\text { Lojas }\end{array}$ & 1500 & 1800 & 2200 & 2500 & 2807 & 3056 & 3214 & 3.410 & 3.500 & 3.540 \\
\hline
\end{tabular}

INTRATEXTOS, Rio de Janeiro. vol.2, nº 1, pp. 76 - 96, 2010. 


\begin{tabular}{|l|r|r|r|r|r|r|r|r|r|r|}
\hline $\begin{array}{l}\text { Número de } \\
\text { Check outs } \\
\text { (caixas de } \\
\text { venda) }\end{array}$ & 5000 & 5500 & 10000 & 11800 & 12344 & 13667 & 14240 & 16.150 & 17.700 & 19.905 \\
\hline $\begin{array}{l}\text { Área de } \\
\text { vendas (m²) }\end{array}$ & 600 & 830 & 1,1 & 1,16 & 1,37 & 1,56 & 1,95 & 2,1 & 2,14 & 2,21 \\
& mil & mil & milhão & milhão & milhão & milhão & milhão & milhões & milhões & milhões \\
\hline
\end{tabular}

Fonte: SuperHiper Abras set /2006, set/2007 e set/2010

A explicação dada por diversos atores sociais propagadores da formação de centrais de negócios (ABRAS, APAS, Consultores, SEBRAE, etc) é que o sucesso destas empresas, segundo eles, está na capacidade de "cooperação" e "solidariedade" traduzida pelos princípios do "associativismo".

As associações comerciais e de ramos industriais também estão divulgando esta prática como sendo o melhor caminho para o desenvolvimento das pequenas e médias empresas. Na fala do diretor de marketing e comunicação da Asserj:

Não existem mais dúvidas de que o conceito de associativismo é a solução mais eficaz para as pequenas empresas ganharem espaço e conquistarem novos clientes. Os empresários que passam a integrar essa prática, trabalhando em conjunto, conquistam novos horizontes operacionais e no mercado. O associativismo é essencial para dar chances de sobrevivência e sustentabilidade às pequenas empresas. Quando estão sozinhas, são frágeis, e juntas são uma organização de forças. (REVISTA SEBRAE, n.19, p.36).

Além disso, Lucia Morita, presidente da Rede Supervizinho, expressa que "com o grande número de centrais no mercado, umas acabam concorrendo com as outras. A partir do momento de uma união, a concorrência é apenas com as grandes redes". (REVISTA SEBRAE, n.19, p.35).

As justificativas/ vantagens dadas pela cartilha da ABRAS para aderir a este conceito são:

\footnotetext{
${ }^{2}$ Check out se refere aos caixas de supermercado onde o consumidor efetua o pagamento. A contabilização de quantos check outs há em uma loja é importante pois indica a possibilidade de fluxo de saída de mercadoria.
}

INTRATEXTOS, Rio de Janeiro. vol.2, $\mathrm{n}^{\circ} 1$, pp. 76 - 96, 2010. 
- Melhorar e fortalecer as lojas,

- Comprar em conjunto e obter melhores negócios, estreitando, assim, as relações entre fornecedores e varejo,

- Desenvolver projetos e serviços diferenciados para o lojista associado,

- Apoiar ou desenvolver os sistemas contábil, jurídico e de recursos humanos,

- Desenvolver ações de marketing como encartes, folhetos, etc.

Em matéria do jornal Folha de São Paulo de 17/08/2003, o consultor Gouvêa de Souza, especialista em Centrais de negócios do setor supermercadista, expõe que a maioria surge a partir do velho formato de central de compras e evolui para um modelo padronizado, com "cara de franquias".

São vários os aspectos que uma central de negócios pode tomar. Além do mais, elas estão ligadas a uma rede de outros parceiros: indústria, atacado, outros profissionais, associações, ABRAS, SEBRAE, etc ${ }^{3}$.

Em algumas reportagens de jornal, encontram-se as opiniões de fornecedores quanto às vantagens e desvantagens das centrais. Por exemplo, há fornecedores que sugerem a criação de centrais com centro de distribuição, pois com a entrega centralizada podem economizar até $20 \%$ no custo em logística. As indústrias podem participar de feiras de negócios onde entram em contato com as associações de compras. Em alguns casos, há relatos de grandes indústrias que procuram as pequenas centrais (e não mais o contrário - segundo os supermercadistas).

Outra instituição que influencia na formação das centrais de negócios é o SEBRAE que, por meio de programas de apoio de desenvolvimento local - como o Projeto Empreender - ajuda a difundir, não só no setor supermercadista mas em vários outros, o modelo de centrais de negócios. Um consultor do SEBRAE-SP, em reportagem ao Diário do Comércio e Indústria de 22/04/2003 comenta que "o pequeno varejo descobriu a fórmula para ganhar visibilidade no mercado e, por intermédio das centrais, chega à grande indústria e consegue descontos em suas compras".

O SEBRAE difunde a idéia de que concorrente não é inimigo. Segundo Patrícia Mayana, que coordena o Programa de Centrais de Negócios do SEBRAE, "a oposição à

\footnotetext{
${ }^{3}$ É possível questionar a participação e os interesses destes parceiros sobre as centrais de compras, porém, isso se constituiria em inúmeras outras pesquisas.
}

INTRATEXTOS, Rio de Janeiro. vol.2, nº 1, pp. 76 - 96, 2010. 
cooperação é uma questão cultural”. Ela explica que é preciso identificar a medida exata e que "parceria não implica uma cooperação e concorrência contínuas". (REVISTA SEBRAE, 01/08/2006, n. 19, p.37).

A difusão das centrais de negócios tem feito as redes grandes alterem seus formatos. Segundo a declaração de Sussumo Honda no Diário do Comércio e Indústria de 22/04/2003: "grandes redes, como o Pão de Açúcar e Carrefour, estão deixando de lado o formato de hipermercado para a implantação de supermercados menores, semelhantes às chamadas lojas de vizinhança" (...) como esse reduto foi sempre dos pequenos, a batalha será árdua na disputa do consumidor".

É recorrente o argumento de que as pequenas empresas se contrapõem às grandes e por isso, a associação é uma forma de sobrevivência. O futuro a que se aponta é para o crescimento dos pequenos, eles se igualariam aos grandes e competiriam de igual para igual, ou até mesmo se sobreporiam. Essa justificativa não é difundida unicamente pelo SEBRAE, mas também pela ABRAS e outras Associações de representação do setor supermercadistas, como por exemplo a Associação Paulista de Supermercados (APAS) e também aparece nas falas de supermercadistas que assim se justificam e se posicionam frente aos outros.

Mas além das vantagens difundidas pelos atores propagadores, as reportagens também apresentam as dificuldades encontradas tanto pelos supermercadistas individualmente quanto pelas centrais de negócios ao se inserirem neste mercado "associativo".

A dificuldade de várias centrais é criar credibilidade junto aos fornecedores, que em geral, olham para o pequeno negócio com desconfiança. Em associação, um empresário que não cumprir o compromisso com um fornecedor está sob a sanção do grupo uma vez que o descumprimento de um pode afetar a credibilidade de todos frente àquele fornecedor. Na fala de João Kásper, diretor da Capixaba Central de Compras: "se um dos nossos atrasa um pagamento, ligamos e damos um prazo de 48 horas". (Valor Econômico, 15/05/2002). Dessa forma há um mecanismo de controle interno entre os membros da central embora, esse controle do grupo sobre si não se dê sem a pressão externa do fornecedor que também pode, por meio do indivíduo, exercer controle sobre o grupo de empresários de uma central.

As dificuldades frequentemente citadas por supermercadistas se referem a concepções de igualdade dentro do grupo de associados. Todos os associados pagam uma mensalidade igual independentemente do porte da empresa de cada associado. No entanto, há centrais em que as empresas associadas diferem quanto ao porte e número de loja, isso faz com que haja a 
discussão se é justo todos contribuírem com o mesmo valor, ou se este deveria ser proporcional às condições de cada associado.

Esses problemas aparecem não só no caso da mensalidade, mas também em várias outras atividades feitas em conjunto em que se verifica que os custos foram igualmente divididos mas os resultados não são igualmente distribuídos. Aponta-se existir também dúvida freqüente se foi feita a melhor negociação e se as vantagens foram distribuídas igualmente (SUPERHIPER, fev/2000, pp. 57-60).

Há reportagens da revista Giro News (2005) que aponta para uma crise em algumas das centrais de negócios, principalmente em São Paulo, pois há centrais perdendo associados e outras tem seus dirigentes afastados e executivos despedidos.

Em todo Brasil as centrais apresentam exemplos de falência: a central Unisuper no Piauí que funcionou de 1992 a 1999 com 11 supermercadistas e a Rede Super, do Maranhão, encerrada em 1997. Em ambos os casos a reclamação que levou à deterioração do grupo era quanto à igualdade das taxas, sendo que no segundo caso houve ainda o fato de que alguns supermercadistas que se desenvolveram mais graças às compras em conjunto, passaram a fazer negociações por fora, quebrando a união do grupo. Outro relato interessante é o da Cooperativa de Compras e Consumo Pantaneira (Coopecom), de Mato Grosso do Sul, a qual chegou a ter 30 associados mas, em 1995, 6 faliram e o grupo teve que assumir as dívidas destes já que coletivamente tinham crédito junto à indústria. Por isso, a Central mudou seu sistema de compras e passou a emitir nota em nome de cada associado.

Pelas reportagens analisadas, estes fenômenos configurariam em crises destas centrais mas não necessariamente do mercado das centrais de negócio em geral pois procuram explicar e estimular as organizações neste modelo "associativo". João Kásper procura dar uma explicação para estes fatos. Veja a seguir um excerto da reportagem:

Se o associado acha que é caro manter a central, com recursos próprios, ou a central não gera um resultado maior do que seu custo, ou o associado não tem capacidade para medir o retorno de sua participação e deve operar sozinho. Defendo o segundo estilo e tenho aversão ao rótulo de centrais de negócios, que muitos adotaram. (...) A gestão da central deve garantir oportunidades iguais aos sócios e benefícios proporcionais aos seus recursos e as suas necessidades. Por isso, acho mais apropriado chamá-las de centrais de compras e serviços, convencido de que a diferença não é apenas semântica. (GIRO NEWS, 2005, p.9).

INTRATEXTOS, Rio de Janeiro. vol.2, nº 1, pp. 76 - 96, 2010. 
Outros problemas apontados nas reportagens se referem ao gerenciamento de uma organização conjunta, pois, quanto mais complexa, mais burocrática e dispendiosa se torna, exigindo contratação de funcionários deixando várias tarefas da administração do coletivo na mão de terceiros. Ou seja, uma "profissionalização" da organização pode resultar na fragilização dos empresários individualmente quanto a assuntos da própria associação. Outro aspecto que já apareceu como um motivo para a saída de associados foi a distância de várias lojas do centro de distribuição, o que faz com que, para alguns, mais do que para outros, o custo com transporte das mercadorias cresça.

Percebe-se que os problemas enfrentados pelas centrais de negócios não se referem unicamente a questões de custos financeiros, mas sim, de relacionamentos pessoais entre os membros, envolvem as percepções quanto a confiança e reciprocidade, assim como as concepções de justiça e igualdade entre os integrantes ou entre eles e os fornecedores. $\mathrm{O}$ grande desafio das centrais de negócios é conciliar suas percepções de "concorrência" e "cooperação" e compreender estas relações é o objetivo da presente pesquisa.

\section{A pesquisa em São Carlos}

A pesquisa se baseia em entrevistas feitas a 6 dos 10 integrantes da rede são-carlense e outros 6 supermercadistas de São Carlos que atuam independentemente. Todos são citados aqui com nomes fictícios.

Pretende-se uma pesquisa comparativa entre as percepções que esses dois grupos de empresários expressam. Tais comparações serão apresentadas ao longo de texto quando os dados permitirem.

Para contatar as pessoas, primeiramente, procurei a sede da central são-carlense, onde o comprador, único funcionário, foi encontrado. Ele me passou uma relação de nomes e telefones de todos os empresários da central. O primeiro a ser contatado foi o presidente. Uma vez feita a primeira entrevista, contatei outros por telefone. Por mais de uma vez, quando solicitava falar com o proprietário do estabelecimento, um funcionário repassava o telefone a uma pessoa que se identificada como dono(a), porém, ao explicar o meu objetivo dizia não poder responder, então, eu descobria que o proprietário era o marido ou filho desta pessoa. 
Alguns não foram encontrados para a entrevista e outros se recusaram dizendo haver falta de tempo.

Os entrevistados de fora da central foram contatados pessoalmente. Considerei que não seria apropriado procurá-los pela lista telefônica uma vez que eu não teria condições para avaliar se a empresa era de porte similar às da central são-carlense. Guiei-me, portanto, por dois critérios que foram apontados pelo presidente da central aqui estudada: o número de check outs (caixas) e área de venda (o espaço interno disponível para a exposição de produtos). Estes dois critérios são indicadores do volume de venda e são facilmente visíveis a qualquer um que observe.

As entrevistas a todos foram semi-estruturadas, seguindo um roteiro que elaborei como padrão, porém, com cada indivíduo as perguntas podiam variar conforme o entrevistado abrisse a temáticas que possibilitassem novas perguntas. Não houve entrevistas com mulheres, mesmo em casos em que elas são sócias legalmente na empresa, quem tomou a frente para responder à entrevista foram os homens.

A central são-carlense existe desde 2003. Inicialmente, formada por 16 lojas e 14 empresários associados. Ao longo do tempo, 4 associados saíram, no período em que foram feitas as entrevistas eram 12 lojas e 10 empresários associados.

A central de negócios é uma associação sem fins lucrativos que intermedeia compras das empresas associadas. Para manutenção da associação todos os 10 empresários pagam uma mensalidade que correspondem a $1 \%$ das compras que fazem. Além disso, em alguns contratos de parceria com fornecedores estabelece-se que eles doem uma porcentagem do valor da compra. Esses recursos pagam o salário de um comprador da associação, o aluguel da sede e os impostos a ela referentes segundo o comprador da central, esse dinheiro também forma um fundo com o qual é possível fazer compras à vista.

Em São Carlos, a central de negócios é formada por lojas de 1 ou 2 check outs, área de venda em média entre 200 a $300 \mathrm{~m}^{2}$ e de 4 a 8 empregados (em todas elas encontram-se pelo menos um membro da família ajudando). São lojas que se situam em bairros distantes com exceção de 2 lojas que se localizam a 3 quarteirões de distância entre si.

A diretoria da central são-carlense é formada por presidente, vice-presidente, diretor comercial, diretor financeiro, diretor administrativo e conselho fiscal. As eleições são realizadas a cada 2 anos com possibilidade de reeleição. Até 2007 foram realizadas 2 eleições 
sendo que na última foi mantida a mesma diretoria do início. Na eleição seguinte, é obrigatória a mudança de cargos.

Os supermercadistas da central são associados à APAS na qual há um comitê destinado às centrais de negócios que realiza reuniões mensais. Nem todas as centrais do estado de São Paulo são filiadas à APAS. Existem cerca de 25 centrais filiadas. A APAS é apontada pelos entrevistados como a entidade mais importante para o desenvolvimento das centrais de negócios.

\section{A formação da central de negócios: construindo a rede}

Quando se toma conhecimento da existência de centrais de negócios e da quantidade delas no país temos a impressão de que este já é um fenômeno consolidado, uma tendência natural do mercado. No entanto, a sociologia dos mercados nos mostra que os mercados não surgem e nem se alteram espontaneamente e, portanto, devem ser compreendidos a partir das relações sociais que os configuram.

\subsection{Contato com instituições}

A união de empresários não pode ser tomado como uma tendência natural mas sim, deve ser construída ao longo do tempo e por meio de diversos tipos de relações e de atores sociais que sobre ele atuam. O início desta central de negócios se deve a busca de informações feita por alguns de seus integrantes. A seguir, o relato de um dos entrevistados:

Depois de uns 6, 7 anos [como supermercadista], eu já tinha vontade de fazer alguma coisa conjunta. Cheguei a conversar com dois ou três supermercadistas, eles acharam a idéia interessante, mas como fazer isso? Mas como buscar a informação? Como juridicamente funcionava? Aí procuramos alguma coisa na Associação Comercial aqui, na época eles estavam começando o Projeto Empreender e não tinham muita informação ainda.

Aí uma pessoa que eu já tinha conversado antes, que hoje é um dos associados, foi passar férias em Santos e, por coincidência, colocaram um panfleto no carro dele. Ele viu e pensando "era o que o F tinha falado já". Aí ele procurou e foi lá. Chegando aqui, ele me procurou. (...) Chegando lá descobrimos que tinha rede que já tinha 8 anos, 9 anos trabalhando neste conceito. Nós pegamos as informações e

INTRATEXTOS, Rio de Janeiro. vol.2, nº 1, pp. 76 - 96, 2010. 
trouxemos pra cá pra montar a rede são-carlense (...) Hoje fazemos parte da associação. Depois que montamos a Rede são-carlense também nos associamos `a APAS ( Associação Paulista de Supermercado). Nós vamos lá uma vez por mês, foi lá que nós conseguimos as informações ( Fernando, presidente).

A partir desta intenção inicial de um dos empresários, outras organizações foram buscadas, inicialmente, a ACISC e SEBRAE, que atuam em nível local, também outra central de negócios do estado de São Paulo, e posteriormente, a APAS, que atua em nível estadual.

Nestes contatos com outras instituições, os empresários passam a receber conhecimentos para construir uma percepção de mundo e guiar suas ações a partir de categorias advindas destas instituições.

\subsection{Contatos pessoais}

Após a primeira tomada de informações junto a várias organizações e atores, passaram a constituir um grupo que viesse a compor a central de negócios. Houve então um trabalho de busca de empresários com quem pudessem estabelecer laços de cooperação:

\footnotetext{
A gente se conhecia assim, de loja, nem nome a gente conhecia. Eu conhecia alguns porque eu trabalhava com vendas, então eu tinha conhecimento da pessoa. O C, eu já tinha vendido cerveja pra ele, o F também. Isso facilitou também, então a gente começou a fazer visitas nas lojas. "oh N o que você está fazendo?" "estou com um mercadinho, nós estamos querendo montar a rede são-carlense e tal, funciona assim, vem conosco?’. E assim foi. (Nelson, vice-presidente).
}

O atual vice-presidente trabalhava como gerente de uma grande empresa de distribuição de bebidas. Essa rede prévia de conhecidos facilitou o contato com algumas pessoas. Também o atual presidente fez uso da rede de relações construída pelos fornecedores para, através destes, obter informações a respeito dos supermercadistas da cidade:

Primeiro montei uma estratégia de quais os bairros eu gostaria que tivesse uma loja da rede são-carlense, associada. Separei os pontos da cidade. E comecei a conversar 
com os vendedores, os fornecedores. Olha no bairro tal tem uma pessoa assim, assim, a empresa tem porte assim assim, é pessoa fechada, ou aberta à negociação, é pessoa idônea, como é a pessoa? Esse não paga direito, esse paga, esse não é. Os fornecedores foram [?]...aí sai fazendo convite para eles. (Fernando, presidente).

Inicialmente, os critérios de confiabilidade foram dados pelos fornecedores, eles tiveram importante papel por terem acesso a uma rede de contatos. Interessante também é notar que eles faziam julgamento quanto aos cumprimentos da empresa e também quanto à personalidade dos empresários. Informavam não só se "paga direito" mas também se é “pessoa fechada ou aberta a negociação". São critérios importantes não só para a manutenção das relações comerciais mas também para as relações pessoais do grupo.

$\mathrm{Na}$ versão de quem foi chamado a participar da central e hoje é um dos associados:

Começou com o Fernando e o Nelson. Essas duas pessoas passaram a dar um toque para algumas pessoas da cidade. Eles elegeram a partir de vendedores, perguntando para vendedores de pessoas que se enquadravam. $\mathrm{Na}$ época era confiabilidade, ou seja, pessoas que sempre pagaram direitinho, que nunca deram trabalho pra eles, nunca deixaram de pagar duplicata. Aí, eles me convidaram logo no começo. E estou aí até hoje.

\section{- Achou a proposta interessante?}

Na verdade não era nem uma proposta, era uma formação de opinião, a gente fazia isso na sala da casa do Fernando. Aí, o grupo começou a aumentar ai nós fomos pra um salão de festa de um cooperado. Depois nós alugamos um salão pra poder começar mesmo a trabalhar. Aí entramos com CNPJ pra formalizar (Ivo, diretor comercial).

As conversas iniciais com os primeiros empresários convidados não tinham caráter formal e podem ter contribuído para que o grupo criasse entre si uma sociabilidade prévia, antes de estabelecer relações contratuais e comerciais.

O motivo apontado para a existência da central é a concorrência com as grandes cadeias de supermercados que ameaçam a sobrevivência dos pequenos: 
Se a gente não seguir vai ficar igual ao sistema americano, a Walmart. Nos EUA já é assim, é a Walmart e mais uma meia dúzia que domina o mercado, os pequenos vão sumir. Um cara ai fora fala "mas eu vendo bem, eu não vou ser atingido" "por enquanto, na hora que montar uma loja de rede aqui na sua cidade, você vai ter dificuldade, porque ela tem mídia, tem funcionário treinado, tem know how, até você combater vai demorar uns dois, três anos. É capaz de fechar a loja”. Essas lojas grandes, não é que elas tenham preço, elas têm todo um conjunto, o preço é o quinto item que o consumidor vê. Primeiro é atendimento, limpeza, organização, mídia, ambientação, uma série de coisas. Agora, se você tiver tudo isso mais o preço, aí fechou ( Nelson, vice-presidente).

Embora não possam ter certeza de que venha a se instalar uma dessas grandes lojas, eles trabalham a partir desta expectativa. É uma concorrência simbólica, imaginária que lhes guiam as ações e garante a manutenção do grupo. Combatem, antes de tudo, o que as grandes lojas representam para eles.

Nem todos os convidados vieram a fazer parte da central. Na versão de um supermercadista que àquela época foi convidado, porém, não aceitou:

Eles vieram me procurar para me chamar, quando eles estavam montando mas eu não tive interesse.

\section{- Por quê?}

O nosso ramo aí, vou ser sincero, o que sobra de lucro líquido não passa de $4 \%$. Se o faturamento de 100 mil é 4 mil reais, eu acho que é um número muito grande para o que me sobra. Quando eles me procuraram nós discutimos vai ter que ter um comprador, alguém pra cuidar do estoque, tem o transporte. A mercadoria vai chegar tudo nesse depósito, isso vai gerar um monte de custo. Então, eu acho que a idéia é que se juntando eles passam a ser como um grande e conseguem poder de negociação junto aos fornecedores, passam a conseguir preços melhores. Eu achei que essa diferença de preço não pagaria os custos da rede. E outra situação, viver em sociedade, passaria a ser uma suposta sociedade. Quando se compra um produto tem que ser arrecado dinheiro de todos para conseguir honrar esse compromisso. Se concorrência de 2 um fura o olho do outro, imagina 10, 12! Eu pensei, se um não pagar quem vai honrar isso aí? Vai sujar o nome dos outros. Aí eu acho que alguém vai ter que bancar, é uma espécie de condomínio sendo que a gente vê a discussão até hoje. Então eu preferi andar com as minhas pernas. Assim como a Rede Clima tem outros como o X é um atacado. Eles tem esse tipo de coisa, eles oferecem mais

INTRATEXTOS, Rio de Janeiro. vol.2, nº 1, pp. 76 - 96, 2010. 
ou menos nesse estilo. Vieram me oferecer mas eu não tive coragem de entrar porque a gente termina se amarrando às pessoas. A minha liberdade é melhor que tudo. Eu tive sócio na padaria e a experiência não foi nenhum pouco agradável, agora eu vou me amarrar a vários sócios? (....) Você pode anotar, ninguém acha que está bom o seu negócio. A galinha do vizinho é sempre mais gorda (Fabiano, supermercadista independente).

Este entrevistado pensa a estrutura da organização da Central similar a um atacado ou a uma sociedade. O que um integrante da central chamaria de "individualismo", para ele é "liberdade" e entende que um grupo lhe negaria isso.

O presidente da central hoje justifica a posição dos empresários que se recusaram da seguinte forma: "Muitos acharam a idéia interessante, outros disseram que trabalham bastante e não tinham tempo pra isso, outras não entenderam nada do conceito" (Fernando, presidente).

\begin{abstract}
Nós iniciamos com 16 lojas mas infelizmente 4 saíram. Um por problema financeiro, outro por não entender o conceito, outros 2 por porte de loja muito diferente das nossas. O que ele precisava comprar pra alcançar o volume que nós precisávamos terminou não compensando pra ele. Aí começou a ter que aumentar o capital de giro sem ter o capital. "O conceito é bom mas eu não posso acompanhar o ritmo de vocês" ( Fernando. presidente).
\end{abstract}

\title{
- Os que estão hoje, estão desde o começo?
}

Sim, algumas saíram, ficaram pelo caminho. Por que no associativismo a gente tem que pensar não no Eu, Eu. Tem que pensar Nós. Então tem pessoas que tem essa dificuldade de pensar no grupo. O quê que é melhor para o grupo. Às vezes não é o melhor pra mim, mas eu tenho que acatar porque eu estou no grupo (Nelson, vice-presidente).

- Caso alguém queira sair da rede pode sair a qualquer momento? Pode sair. Faz uma carta, assina tudo bonitinho, entendeu? (Nelson, vice-presidente).

O primeiro entrevistado usou do fato de duas pessoas terem saído para confirmar o valor do conceito do associativismo, pois até entre dois dos que saíram havia o reconhecimento de que o " conceito é bom”. Já o segundo entrevistado, não fez diferenciações 
entre os motivos para as 4 desistências. Para ele, todas as saídas se justificam pelo “individualismo". Na versão de um dos empresários que saíram da central:

Fizemos parte da Rede Clima. Fizemos parte por 2 anos e meio mais ou menos.

- Qual o motivo para ter saído?

No nosso caso não deu muito certo talvez por causa da proximidade com outros supermercados, então a gente tinha necessidade de comprar outros produtos e que de repente eles não tinham, não trabalhavam ou com aquela quantidade de itens, então você fica meio amarrado nisso (Ronaldo, supermercadista independente).

A loja deste entrevistado tem um porte maior que a dos integrantes da central. Possui 4 check outs e uma área de pelo menos $500 \mathrm{~m}^{2}$, também pude observar que se localiza em uma área central da cidade, em uma rua com maior fluxo do que as lojas dos demais associados da central. Primeiramente, vê-se que ele alega a proximidade com outra loja, assim, mesmo não fazendo mais parte da central, ele reafirma uma norma contida nela.

\section{Os limites de crescimento da rede}

No que se refere à aceitação de novos empresários na central existem critérios tanto formais estabelecidos em estatuto, quanto informais para limitar a entrada de novos associados:

Sim, já tentaram [se associar] mas a gente analisa bem porque envolve um monte de coisas, inclusive aspecto jurídico. É uma associação, todo mundo assina e a rede é responsável pelas compras, apesar das compras serem individuais, a rede é responsável. Então a gente fica com pé atrás, analisa bem, como ele é, se tem cabeça para o associativismo e assim por diante (Nelson, vice presidente).

O perfil básico hoje é não ter menos que $2000 \mathrm{~m}$ de distância de uma loja da rede são-carlense senão vai interferir. Se fica muito próximo, por mais que fale que é parceiro... talvez você coloque duas lojas juntas hoje não vai ter problema, mas à medida que vai desenvolvendo trabalhos de marketing e mídia a tendência é começar a crescer, então se uma loja fica muito próxima da outra, uma vai barrar o

INTRATEXTOS, Rio de Janeiro. vol.2, nº 1, pp. 76 - 96, 2010. 
crescimento da outra. É um dos conceitos que nós trouxemos de lá. Então, aquela que fica mais dinâmica vai sobreviver e a outra vai morrer, não tem jeito.

Outro critério é o tempo de fundação da loja, a gente não pega loja com menos de 2 anos de fundação. Porquê não tem o perfil do empresário, você não sabe se ele está no mercado por aventura, se ele é realmente bom pagador, se vai trazer problema pra rede, se tem risco de falência.

E um terceiro critério é ter loja com faturamento próximo das nossas, por duas experiências que nós temos, de pegar loja com faturamento bem inferior, com um percentual pra baixo ou pra cima. Também não pode ser muito acima senão o cara vai achar que pode mandar mais. Hoje está mais ou menos igual (Fernando, presidente).

Os associados procuram analisar previamente a possibilidade de o empresário candidato cumprir ou não às regras do grupo. Essas regras podem exigir que o associado abra mão de antigos parceiros de negócios e de outras relações de confiança anteriores. Este é o custo (não apenas econômico) de entrar em um grupo já estabelecido. Não dar preferência para um fornecedor parceiro é não cumprir com as regras do grupo.

Até aqui, vimos quais as regras que criam fronteiras entre os de dentro e os de fora da central. Constituem-se em critérios para aceitação de um novo associado e julgamentos aos que dela saem.

\section{Considerações finais}

No caso estudado, empresas em bairros distantes, inicialmente, não tinham relação entre si, faziam parte do mercado de supermercados da cidade mas exploravam nichos locais. No entanto, a central são-carlense permitiu criar relações de sociabilidade entre pessoas que antes não se conheciam e também relações econômicas onde antes não existiam. Como já mencionado, a percepção de concorrência se reconfigurou para o grupo.

A central são-carlense teve inicio quando indivíduos começaram a buscar instituições e redes de relações já existentes para construir a rede da central de negócios. Estas redes prévias forneceram informações aos empresários. Os fornecedores e associações fazem parte dos laços fracos construídos pelos supermercadistas da central pois as relações são constantes mas não tão freqüentes quanto as relações internas do grupo de empresários da central.

INTRATEXTOS, Rio de Janeiro. vol.2, nº 1, pp. 76 - 96, 2010. 
Essa rede de laços fracos é importante como fonte de informações e, assim, têm um importante papel na difusão da concepção de associativismo e das inovações no setor e também em nível local são fontes de informação a respeito de outros empresários. Isto permite a constituição de percepções quanto a possibilidade de confiança ou concorrência com aqueles que estão fora da central.

Assim, vai se configurando a rede fechada de supermercadistas da central. Nesta rede a entrada e saída de seus membros é controlada tanto por normas legais quanto por normas informais que se baseiam nas percepções de confiança. Nesta rede fechada forma-se um grupo coeso de empresários que compartilham não só dos negócios da Central mas também demonstram existir laços fortes que vão além dos econômicos pois as famílias se conhecem e se encontram com certa freqüência.

Sucintamente, neste paper, mostrou-se a formação e manutenção de uma organização em rede. Além disso, propôs-se pensar também os limites e as combinações possíveis entre a cooperação e o interesse econômico, reconhecido pelos próprios empresários como um problema enfrentado pelas centrais de negócios.

Este estudo de caso não teve a intenção de levantar conclusões definitivas, mas sim, de apresentar ao leitor as centrais de negócios como objetos relevantes para a análise sociológica, e que ainda permanecem pouco estudadas.

\section{REFERÊNCIAS BIBLIOGRÁFICAS}

ABRAS. “A $7^{\mathrm{a}}$ pesquisa Ranking de Redes e Associações de Negócios”. In: SUPERHIPER. Ano 33, n. 379, Setembro 2007.

ALARCON, Tatiana. "Cooperar para competir, ensina a sabedoria milenar". Revista SEBRAE, n. 19. 01/08/2006.

ALBAGLI, S; MACIEL, M.L. "Capital Social e Desenvolvimento Local”. In: H.M.M Lastres, J.E Cassiolato, M.L Maciel (Orgs). Pequena empresa: cooperação e desenvolvimento local. Rio de Janeiro: Relume Dumará, 2003.

BARCELLOS, Marta. "Pequenos unem-se contra gigantes”. Valor Econômico. 15/05/2002. BOLTANSKI, L; Chiapello, E. "El Nuevo Espíritu del Capitalismo”. In: Cuestiones de Antagonismo. Akal: Madrid, 2002.

BOURDIEU, P. “O campo econômico”. In: Política e Sociedade. n.6, abril de 2005. 
CASSIOLATO, J.E.; LASTRES, H.M.M. "O foco em arranjos produtivos e inovativos locais de micro e pequenas empresas”. In: H.M.M Lastres, J.E Cassiolato, M.L Maciel (Orgs). Pequena empresa: cooperação e desenvolvimento local. Rio de Janeiro: Relume Dumará, 2003.

COSTA, Vivian. "Fornecedor sugere central unificada". Diário do Comércio e Indústria. 27/05/2003.

DURKHEIM, E. “A divisão do trabalho social”. In: Pensadores. v.64. $2^{a}$ ed. São Paulo: Abril Cultural, 1983.

ELOI, Cristiano. "Centrais de compras lideram expansão de venda do setor". DCI: caderno comércio. 14/09/2006.

FACCHINI, Claudia, Bueno, Sérgio. "Centrais de compras amadurecem e dão músculo ao pequeno varejo". Valor. Caderno empresas. 13/02/2006.

FUNDAÇAO ABRAS. 50 anos dos supermercados no Brasil. São Paulo: Informe Brasil, 2002.

FURLAN, Márcia. "Centrais de compras brigam pela legalidade”. O Estado de São Paulo. 23/09/2003.

GHISI, F. A. Fatores críticos na sustentabilidade das centrais de negócios no setor supermercadista. Tese (doutorado) - Departamento de Administração, Ribeirão Preto: USP, 2005 .

GRANOVETTER, M. “Ação econômica e a estrutura social: o problema da incrustação". In: In: R. Marques, João Peixoto (orgs). A nova Sociologia Econômica. Oeiras: Celta Editora, 2003.

The Economic Sociology of Firms and Entrepreneurs. In: R. SWEDBERG (org.). Entrepreneurship: the social sciense view. New York: The Oxford University Press, 2000. HILÁRIO, Wagner. "Centrais Paulistas perdem associados". DCI: caderno comércio. 20/07/2005.

KASPER, João Francisco de Pinedo. "As centrais de negócios estão passando por uma 'crise de crescimento'?” In: Revista Giro News. São Paulo: julho/2005.

LIMA, Bruno. "Centrais do Brasil: central soma forças e se multiplica”. Folha de São Paulo. São Paulo: 17/08/2003. Disponível em <http://www.folha.com.br>.Acessado em 11/10/2007. 
MATTEDI, C. “A construção social do mercado em Durkheim e Weber uma análise do papel das instituições na sociologia econômica clássica". Revista Brasileira de Ciências Sociais, v.20 n. 57, fev/2005.

MAUSS, Marcel. Sociologia e antropologia. Mauro W. B. de Almeida (Trad.). São Paulo: E.P.U., 1974.

MELO, Natália Maximo e. SEBRAE e empreendedorismo : origem e desenvolvimento. Dissertação (Mestrado). São Carlos: UFSCar, 2008.

MOREIRA, Célia. "Pequenos decidem formar megacentral". Diário do Comércio e Indústria. 22/07/2003.

"Centrais de compras crescem 50\% ao ano". Diário do Comércio e Indústria. 22/04/2003.

SMELSER, N. e R. SWEDBERG. "The sociological perspective on the economy". In: The Handbook of Economic Sociology. Princeton: Princeton University Press. 1994.

WEBER, Max. Economia e sociedade: fundamentos da sociologia compreensiva. Brasília: UnB, 1991. 